\title{
Recovering and preventing loss of detailed memory: differential rates of forgetting for detail types in episodic memory
}

\author{
Melanie J. Sekeres, ${ }^{1}$ Kyra Bonasia, ${ }^{2}$ Marie St-Laurent, ${ }^{1}$ Sara Pishdadian, ${ }^{2}$ \\ Gordon Winocur, ${ }^{1,2,3,4}$ Cheryl Grady, ${ }^{1,2,3}$ and Morris Moscovitch ${ }^{1,2,5}$ \\ ${ }^{1}$ Rotman Research Institute, Baycrest, Toronto, Ontario, M6A $2 E 1$ Canada; ${ }^{2}$ Department of Psychology; ${ }^{3}$ Department of Psychiatry, \\ University of Toronto, Toronto, Ontario, M5S $3 \mathrm{G} 3$ Canada; ${ }^{4}$ Department of Psychology, Trent University, Peterborough, Ontario, \\ K9] 7B8 Canada; ${ }^{5}$ Department of Psychology, Baycrest, Toronto, Ontario, M6A $2 E 1$ Canada
}

\begin{abstract}
Episodic memories undergo qualitative changes with time, but little is known about how different aspects of memory are affected. Different types of information in a memory, such as perceptual detail, and central themes, may be lost at different rates. In patients with medial temporal lobe damage, memory for perceptual details is severely impaired, while memory for central details is relatively spared. Given the sensitivity of memory to loss of details, the present study sought to investigate factors that mediate the forgetting of different types of information from naturalistic episodic memories in young healthy adults. The study investigated (1) time-dependent loss of "central" and "peripheral" details from episodic memories, (2) the effectiveness of cuing with reminders to reinstate memory details, and (3) the role of retrieval in preventing forgetting. Over the course of $7 \mathrm{~d}$, memory for naturalistic events (film clips) underwent a time-dependent loss of peripheral details, while memory for central details (the core or gist of events) showed significantly less loss. Giving brief reminders of the clips just before retrieval reinstated memory for peripheral details, suggesting that loss of details is not always permanent, and may reflect both a storage and retrieval deficit. Furthermore, retrieving a memory shortly after it was encoded prevented loss of both central and peripheral details, thereby promoting retention over time. We consider the implications of these results for behavioral and neurobiological models of retention and forgetting.
\end{abstract}

[Supplemental material is available for this article.]

A rich literature on time-dependent forgetting indicates that multiple mechanisms including, for example, memory decay (Thorndike 1913), and interference (Keppel and Underwood 1962) contribute to the forgetting of information (see Hardt et al. 2013; Sadeh et al. 2014 for review). Forgetting is not an all-or-none process; differential rates of forgetting have been identified for different aspects of a memory (Bahrick 1984; Conway et al. 1991; Brainerd and Reyna, 1993). Episodic memory, the conscious recollection of autobiographical events, contains contextspecific information (i.e., sensory, perceptual, affective information), that can be retrieved and re-experienced in rich detail (Tulving 1972, 1983; Anderson and Conway 1993; Brewer and Pani 1996). Episodic memories are particularly susceptible to loss of detail information (Tulving 1972), with central elements critical to the overall coherence of an event more likely to be retained (Thorndyke 1977; Rumelhart and Ortony 1977). These distinctions have been observed in studies in which participants, after reading a narrative, preferentially recall story elements that affect overall plot coherence (central elements or gist), over details (peripheral elements) that are less critical to the plot (Thorndyke, 1977; Bahrick 1984; Conway et al. 1991). This pattern of recollection is consistent with memory theories which propose that both the gist and the contextually detailed elements of an episodic memory may be extracted, and while either type of detail may support memory retrieval, gist elements tend to be primarily re-

Corresponding author: msekeres@research.baycrest.org

Article is online at http://www.learnmem.org/cgi/doi/10.1101/lm.039057. 115 . lied upon as a memory ages (Brainerd and Reyna 2002; Conway et al. 2009; Winocur and Moscovitch 2011). Consistent with this idea, in a series of studies using a short documentary film to test time-dependent changes in the quality of episodic memory in healthy controls, Furman et al. $(2007,2012)$ found that questions pertaining to the film's "plot theme" were accurately recognized over time, whereas cued recall of contextual details showed a steep decline over the weeks following encoding.

Studies of patients with medial temporal lobe damage have shown that the peripheral details of an episodic memory are disproportionately sensitive to hippocampal damage (Rosenbaum et al. 2005; Steinvorth et al. 2005; Gilboa et al. 2006; St-Laurent et al. 2009), highlighting the critical role of the hippocampus in recalling detailed memory. Apart from differential forgetting rates, little is known about the factors that influence forgetting of central elements and peripheral details of naturalistic stimuli. Previous studies have examined the effects of cuing and repeated retrieval on forgetting, but it is not clear whether effects of cuing and repeated retrieval, that typically have been examined separately for laboratory-based stimuli such as words and sentences, would also apply to more complex material of the sort that constitute autobiographical memories. The aim of the present study was

\footnotetext{
C 2016 Sekeres et al. This article is distributed exclusively by Cold Spring Harbor Laboratory Press for the first 12 months after the full-issue publication date (see http://learnmem.cshlp.org/site/misc/terms.xhtml). After 12 months, it is available under a Creative Commons License (AttributionNonCommercial 4.0 International), as described at http://creativecommons. org/licenses/by-nc/4.0/.
} 
to systematically probe various factors that influence the natural loss, and retention, of different qualitative elements of naturalistic memory content over time, using a controlled, ecologically valid paradigm that mimics real-life episodic memory. To address these various issues, we conducted a series of experiments in which participants watched 40 brief film clips, encoding each episode during a single session. After varying delays, participants verbally recalled central and peripheral details of the events contained in the clips (see St-Laurent et al. 2014 for a similar approach). Film clips offer an ecologically valid approach to studying changes in episodic memory over time, since they are dynamic, continuous, and contain perceptual and affective narrative elements within a spatial-temporal context (Furman et al. 2007, 2012; Hasson et al. 2008), Thus, they capture some of the complexity of real world events, while retaining the reproducibility and controlled nature of more traditional laboratory stimuli (Furman et al. 2007; Mendelsohn et al. 2010; St-Laurent et al. 2014).

In Study 1, we tested the hypothesis that different types of event information are forgotten at different rates. Here, participants recalled memory for film clips at varying delays ranging from several minutes to a full week following encoding. Based on the existing literature (Thorndyke 1977; Bahrick 1984; Conway et al. 1991), we predicted faster loss of context-specific peripheral details than central story details. In Study 2, we examined whether peripheral memory details are permanently lost (reflecting a storage deficit), or whether they could be retrieved when appropriately cued with a reminder. The latter outcome would indicate that it is possible to reinstate an apparently forgotten detailed memory episode, and would be in line with evidence that providing primarily perceptual cues associated with encoding promotes episodic memory retrieval (Howard and Kahana 2002; see Ryan et al. 2015, Tonegawa et al. 2015 for neurobiological evidence). However, the previous studies did not address the effectiveness of a cue in enhancing the retrieval of qualitatively different elements from a memory.

In Study 3, we sought to determine whether repeated retrieval of naturalistic events could render episodic details more resistant to time-dependent loss and, if so, does it increase the likelihood that either central or peripheral elements, or both, will be accessible for later retrieval. Previous studies have found that actively retrieving a memory following encoding protects against forgetting far better than re-encoding the information, a phenomenon referred to as the "testing effect" (Gates 1917; Spitzer 1939; Tulving 1967; Carrier and Pashler 1992; Roediger and Karpicke 2006; Karpicke and Roediger 2008; for recent reviews, see Roediger and Butler 2011; Rowland 2014). The testing effect has been studied using simple stimuli such as paired associates (Carpenter et al. 2006; Pyc and Rawson 2007; Karpicke and Roediger 2008; Toppino and Cohen 2009), word list learning (Wheeler et al. 2003; Carpenter and DeLosh 2006; Rowland and DeLosh 2014), and visuospatial information (Carpenter and Pashler 2007; Kang 2010), but has not been examined in the context of naturalistic episodic memory. Here we ask if retrieving a naturalistic memory can strengthen the representation of either, or both, central and peripheral details, attenuating the loss of one or both types of elements over time. Together, using a paradigm for testing naturalistic memory, these three studies investigated the differential rates of forgetting for the types of detail that comprise episodic memory, and explored ways of cuing their recovery and preventing their loss.

\section{Results and comment}

\section{Study l: time-dependent loss of memory for peripheral (episodic) and central details}

We first investigated the prediction that, in recalling specific film clips, participants will show greater time-dependent loss of peripheral details than of central details associated with the general storyline. A $2 \times 3$ repeated-measures ANOVA was conducted with "Detail" (central and peripheral) and Delay (0-, 3-, 7-d) as withinsubject factors, and "Retrieval Success" as the dependent variable (also see Supplemental Results). The ANOVA revealed significant main effects of Detail, with more peripheral details recalled than central details $\left(F_{(1,5)}=8.03, P=0.037\right)$ and of Delay $\left(F_{(2,10)}=\right.$ 38.611, $P<0.001)$. A linear contrast indicated that memory decreased over time $(0>3>7 \mathrm{~d} ; P=0.01)$ for both types of details, indicating that participants recalled fewer details at longer delays. A significant Detail $\times$ Delay interaction $\left(F_{(2,10)}=17.67, \quad P=\right.$ 0.001 ) also was observed. Although there was a significant decline between the immediate and 7-d tests sessions for both central $\left(t_{(7)}=7.401, P=0.001\right)$ and peripheral details $\left(t_{(7)}=7.098, P=\right.$ $0.001)$, consistent with our hypotheses, peripheral details were lost at a faster rate and to a greater degree than central details. This is reflected in the significantly greater percentage loss for peripheral details than central details $\left(t_{(7)}=-6.321, P<0.0001\right)$, where central details declined by $28.09 \%$ (SE 3.86) between the 0 - and 7-d retrieval sessions, and peripheral details declined by $65.21 \%$ (SE 5.24) (Fig. 4A below). Further evidence for the preferential retention of central details comes from the shift over time from the first retrieval session, where significantly more perceptual details were recalled than central details $\left(t_{(10)}=-6.11, P<\right.$ 0.001 ), to the $3-\mathrm{d}$ retrieval session where this difference is only marginal $\left(t_{(8)}=-2.06, P=0.07\right)$, and finally to the 7 -d retrieval session where equivalent numbers of central and peripheral details are recalled $\left(t_{(7)}=0.85, P=0.42\right.$ ) (Fig. 1B). Together, these
A

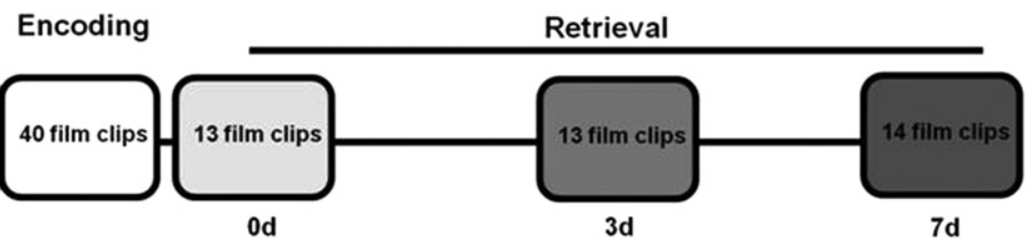

B
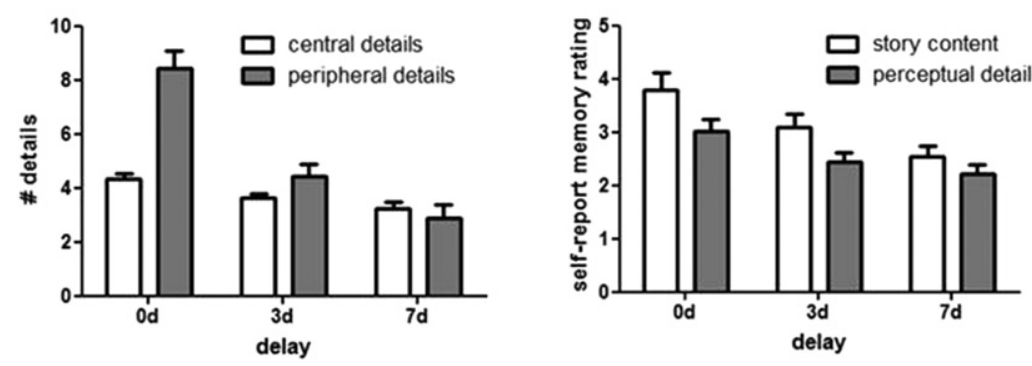

Figure 1. Time-dependent loss of memory for peripheral details. $(A)$ Schematic of the experimental timeline for Study 1. ( $B$, left) Number of details (central and peripheral) reported during the memory retrieval test session at each delay (0-, 3-, and 7-d delay). (Right) Self-report memory rating of the story content and the vividness of perceptual details for each memory retrieval test session. 
results suggest that, while memory for the rich episodic peripheral elements of the film clips declined steeply, memory for the general storyline showed minimal loss over the week following encoding (Fig. 1B, see Supplemental Results). We also conducted similar analyses using the percentage of details forgotten to exclude the possibility that the differential rates of forgetting for central and peripheral details over time were due to differences in the number of retrievable details that were possible (see Materials and Methods). Comparable results were seen in these analyses (see Supplemental Results).

A Detail $\times$ Delay ANOVA was also conducted with selfreport memory ratings as the dependent variable. ANOVA revealed significant main effects of Detail, with participants choosing higher ratings for story content than for perceptual content $\left(F_{(1,5)}=13.70, \quad P=0.014\right)$ and of Delay $\left(F_{(2,10)}=17.68, P=\right.$ $0.001)$, with a linear decrease in memory ratings across the 3 delays $(0>3>7 \mathrm{~d} ; P=0.005)$. A significant Detail $\times$ Delay interaction $\left(F_{(2,10)}=10.78, P=0.003\right)$ was also found, with post hoc tests indicating that memory ratings declined more for story content than for perceptual content over time. Although participants rated their memory for story content higher than their memory for perceptual content at the first $\left(t_{(10)}=3.75, P=\right.$ $0.004)$ and second retrieval sessions $\left(t_{(8)}=4.05, P=0.004\right)$, ratings were equivalent for both the story content and perceptual content by the 7 -d retrieval session $\left(t_{(7)}=1.97, P=0.090\right.$ ) (Fig. $2 B)$. Furthermore, self-ratings of memory for story content were significantly lower at $3 \mathrm{~d}$ than at immediate testing $\left(t_{(8)}=\right.$ 3.873, $P=0.005$ ), and significantly lower at $7-\mathrm{d}$ than at 3 -d retrieval $\left(t_{(5)}=2.698, P=0.043\right)$, while self-ratings of perceptual content declined between immediate testing and the $3 \mathrm{~d}$ retrieval $\left(t_{(8)}=2.919, P=0.019\right)$, but not between the 3- and 7-d retrieval sessions $\left(t_{(5)}=2.421, P=0.060\right)$. Taken together, the results of Study 1 revealed greater loss of peripheral memory details, with preferential retention of central story details, despite the finding that participants' self-reported ratings for their memory of story

\section{A}

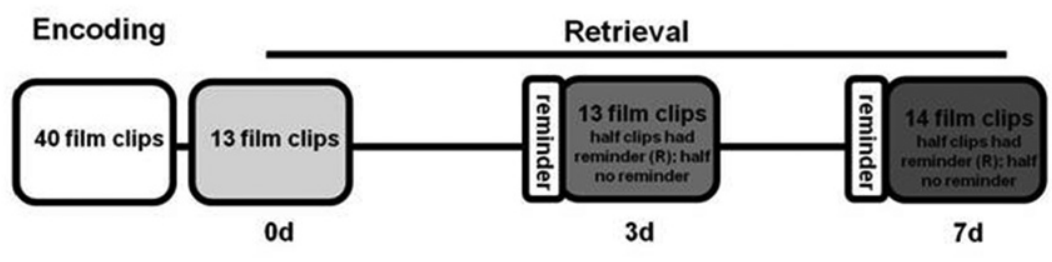

B
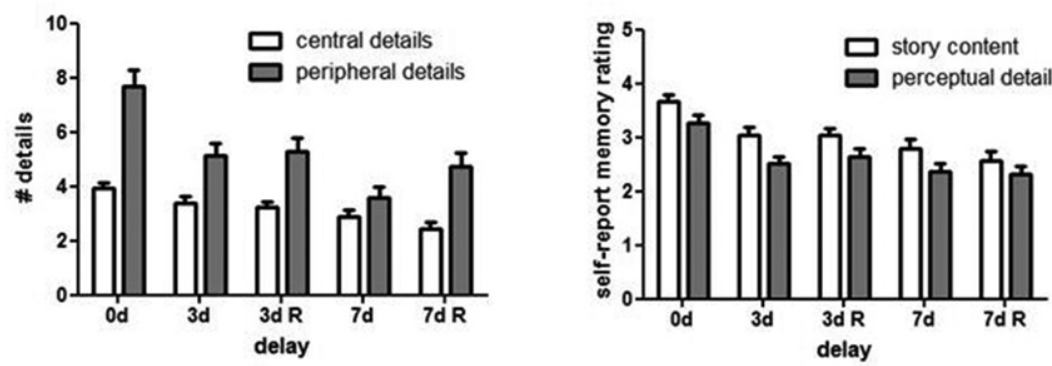

Figure 2. Reactivation of the remote memory reinstates memory precision. $(A)$ Schematic of the experimental timeline for Study 2. ( $B$, left) Number of details (central and peripheral) reported during the memory retrieval test session at each delay (0-, 3-, and 7-d delay). (Right) Self-report memory rating of the story content and the vividness of perceptual details for each memory retrieval test session. Prior to the 3- and 7-d delay test session, reminders were presented for half the clips in the series. Data are presented for the reminded clips (R), and the nonreminded clips tested at each delay. Note that reminders were not given prior to the immediate (0-d) memory test session. details was typically higher than for perceptual details, but then declined over time. The discrepancy between self-report ratings and objective findings will be addressed in the Discussion section.

\section{Study 2: reactivation of a remote memory promotes retrieval of memory details}

We were next interested in whether the apparently lost central and peripheral details could be recovered by briefly reactivating the memory. That is, we assessed whether central and peripheral memory just prior to testing. The results confirmed that both central and peripheral details were lost over time, with peripheral details lost at a faster rate and to a greater degree than central details. Importantly, however, reminders were effective in restoring some of the peripheral detail for the 7-d-old memories but not the central details.

Replicating the results of Study 1, the Detail $\times$ Delay ANOVA of nonreminded clips revealed a significant main effect of Detail, with more peripheral details recalled than central details $\left(F_{(1,15)}=\right.$ $21.445, P<0.001$ ), and of Delay, with details forgotten over time $\left(F_{(2,30)}=31.124, P<0.001\right)$. There was also a significant interaction between Detail and Delay $\left(F_{(2,30)}=27.068, P<0.001\right)$, such that peripheral details once again declined to a significantly greater degree than central details over the 7-d delay $\left(t_{(16)}=-3.643\right.$, $=0.002$ ), with peripheral details declining by $52.61 \%$ (SE $4.82 \%$ ) and central details declining by 26.20\%) (SE 7.02\%). Again replicating Study 1, participants reported significantly more peripheral details than central details during the 0 -d retrieval test $\left(t_{(17)}=-6.40, P<0.001\right)$, but equivalent numbers central and peripheral details in the 7-d retrieval session $\left(t_{(18)}=-1.61, P=0.13\right)$ (Fig. 2B). Although central and peripheral details were both lost over time $\left(t_{(16)}=3.781, P=0.002\right.$ and $t_{(16)}=7.809, P=0.0001$, respectively) as mentioned previously-a significantly greater percentage of peripheral details were lost, while central details were preferentially retained (see statistic values above).

A $2 \times 2 \times 2$ repeated-measures ANOVA was performed on the data, using Detail (central and peripheral), Delay (3-, 7-d), and Reminder (nonreminded-NR, reminded-R) as within-subject factors, and Retrieval Success as the outcome variable. The immediate $(0-d)$ delay could not be included here because it lacked the reminder condition. These data were analyzed in a separate ANOVA that included only nonreminded data (reported above), and was thus equivalent to the analysis for Study $1(2 \times 3$ ANOVA for Detail $\times$ Delay). The Detail $\times$ Delay $\times$ Reminder ANOVA revealed significant main effects of Detail, with participants recalling fewer central details overall $\quad\left(F_{(1,17)}=19.03, \quad P=\right.$ 0.001 ), and of Delay, with participants recalling fewer details over time $\left(F_{(1,17)}=\right.$ $14.03 P=0.002)$, but a nonsignificant main effect of Reminder $\left(F_{(1,17)}=0.93\right.$, $P=0.35)$. As predicted, a significant Detail $\times$ Reminder interaction $\left(F_{(1,17)}=\right.$ $10.30, P=0.005)$ was observed. All other 
interactions were nonsignificant (all $P$ 's $>0.13$ ). Post hoc analyses of the Detail $\times$ Reminder interaction showed the reminder had no effect on either central $\left(t_{(17)}=0.629, P=0.54\right)$ or peripheral $\left(t_{(17)}=-0.302, P=0.77\right)$ details at the 3 -d delay. However, at the 7-d delay, reminders enhanced the number of peripheral details reported $\left(t_{(17)}=-2.279, P=0.036\right)$, without significantly affecting the retrieval of central details $\left(t_{(17)}=1.77, P=0.095\right)$. Consistent with this significant effect of the reminder on memory for peripheral details at the 7-d delay, the percentage of details lost between 0- and 7-d retrieval sessions for reminded clips no longer differed between central $(38.20 \%$, SE $7.50 \%)$ and peripheral $(35.46 \%$, SE $6.40 \%)$ details $\left(t_{(16)}=3.22, P=0.751\right)$ (Fig. $4 \mathrm{~B}$ below). Thus, the reminder had no significant effect on memory for central details at any time, while significantly improving recall of peripheral details at the longest delay. However, the reminders were ineffective at enhancing memory retrieval at the 3-d delay. This result is consistent with the idea that episodic memory is susceptible to loss over time, but that cuing can lead to the partial recovery of faded detailed memory (Figs. 2B, 4B).

A $2 \times 2 \times 2$ ANOVA was conducted for self-report memory ratings, which revealed significant main effects of Detail, with memory for perceptual content rated lower than memory for story content $\left(F_{(1,17)}=22.78, P<0.001\right)$, and of Delay, with memories rated significantly higher at 3-d than at 7-d retrieval sessions $\left(F_{(1,17)}=6.93, P=0.017\right)$. The main effect of Reminder was not significant $\left(F_{(1,17)}=0.010, P=0.76\right)$, and there were no significant interactions (all $P$ 's $>0.061$ ), suggesting that the reminders did not affect the subjective quality of the memories (Fig. 2B).

Taken together, the results of Study 2 suggest that cuing a remote episodic memory just prior to retrieval can partially restore peripheral details, without significantly affecting memory for central details. Thus, the central elements, or gist, of a memory do not seem to be as susceptible to decline or enhancement as the perceptual elements that characterize an episodic memory. study, participants retrieved all 40 film clips immediately after encoding, and subsequently reretrieved subsets of clips at 1-, 3-, and 7-d delays. In this way, each clip was tested twice. As predicted, prior retrieval enhanced memory-the number of both central and peripheral details recalled remained stable across the retrieval sessions. Despite the retention of both types of detail, participants still rated their memories as weaker across the delays. This suggests that, subjectively, people felt they were forgetting information, despite the fact that they recalled an equivalent number of central and peripheral details at all time points.

A $2 \times 4$ repeated-measures ANOVA was conducted with Detail (central and peripheral) and Delay (0-, 1-, 3-, 7-d) as withinsubject factors, and Retrieval Success as a dependent variable. The ANOVA revealed a significant main effect of Detail, with peripheral details recalled at a higher rate than central details $\left(F_{(1,9)}=7.69, P=0.02\right)$, but a nonsignificant main effect of Delay $\left(F_{(3,27)}=0.70, P=0.56\right)$, and a nonsignificant Detail $\times$ Delay interaction $\left(F_{(3,27)}=1.02, P=0.80\right)$, indicating no significant decline of either central or peripheral details over time (Fig. $3 \mathrm{~B})$. A planned comparisons $t$-test confirmed no significant difference in the percentage loss of central details $(4.60 \%$, SE $3.27 \%)$ and peripheral details (11.10\%, SE $6.72 \%)$ between the 0 - and 7 -d retrieval tests $\left(t_{(10)}=-1.177, P=0.267\right)$ (Fig. $\left.4 \mathrm{C}\right)$. Thus, actively retrieving the memory for the film clips immediately following encoding appears to protect against the loss of central and peripheral details, promoting the retrieval of both types of information over time.

With respect to self-report memory ratings, the ANOVA showed a significant main effect of Delay $\left(F_{(3,27)}=17.42, P<\right.$ $0.001)$, and a significant main effect of Detail $\left(F_{(1,9)}=22.79, P=\right.$ $0.001)$, with memory for story content rated higher than memory for perceptual content. Post hoc analyses revealed a significant linear decrease in ratings over the four retrieval sessions (immediate $>0>3>7$ d; $F_{(1,9)}=28.73, P<0.001$ ) (Fig. 3B). Consistent with the self-report findings in Studies 1 and 2, it

\section{Study 3: retrieving memory immediately following encoding prevents subsequent forgetting of details}

Study 1 demonstrated that different types of episodic memory details are forgotten at different rates over time, with preferential retention of central story elements over peripheral details. Using the same paradigm, Study 2 demonstrated that cuing the episodic memory with a reminder just prior to retrieval can enhance the retrieval of peripheral details, suggesting that "forgotten" details might not be permanently lost, but rather may be inaccessible without appropriate cuing. An outstanding question relates to the factors that mediate the initial forgetting of detail for naturalistic events. In Studies 1 and 2, each clip was retrieved only once, at a delay of 0,3 , or $7 \mathrm{~d}$ following encoding. Based on the idea that active retrieval of recently learned information strengthens later retrieval (Roediger and Butler 2011), we investigated whether retrieving the film clips immediately following encoding would facilitate the retention of either central or peripheral details, or both. In this

\section{A}

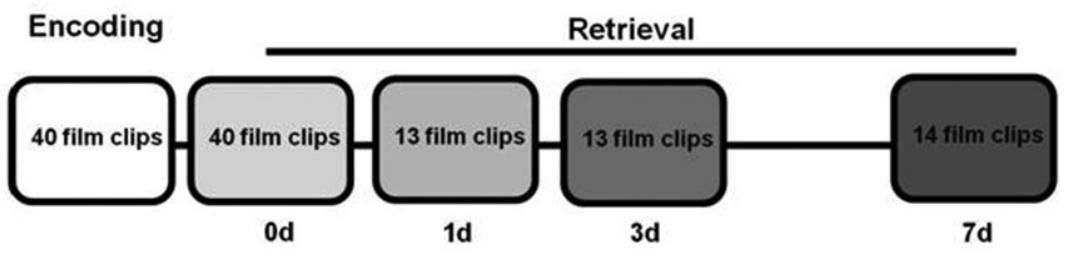

B
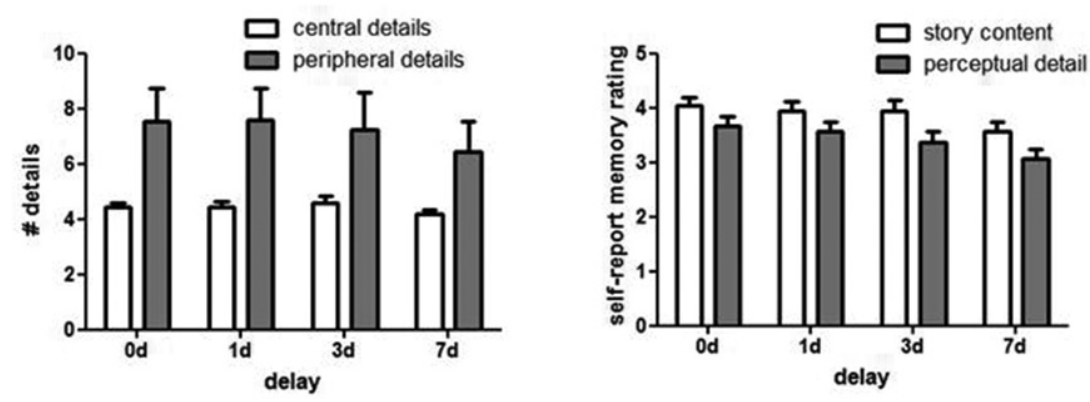

Figure 3. Retrieving memory immediately following encoding prevents the forgetting of peripheral details in remote memory. $(A)$ Schematic of the experimental timeline for Study 3 . ( $B$, left) Number of details (central and peripheral) reported during the memory retrieval test session at each delay $(0,1,3$, and 7-d delay). (Right) Self-report memory rating of the story content and the vividness of perceptual details for each memory retrieval test session. 
A
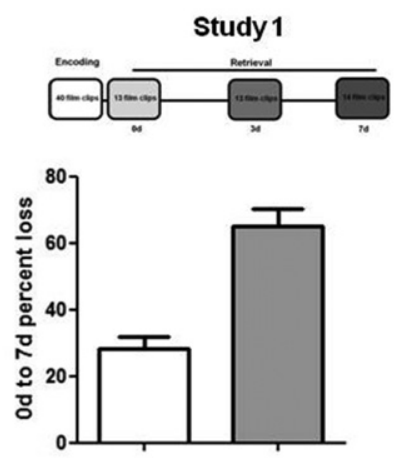

B
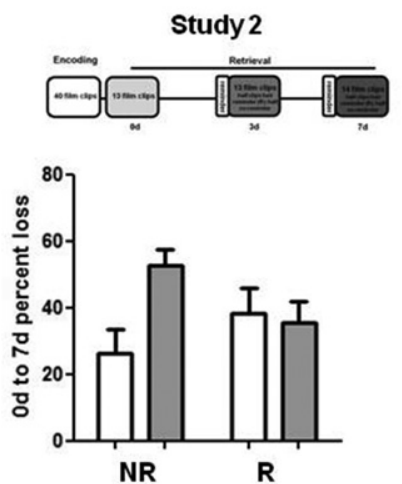

C
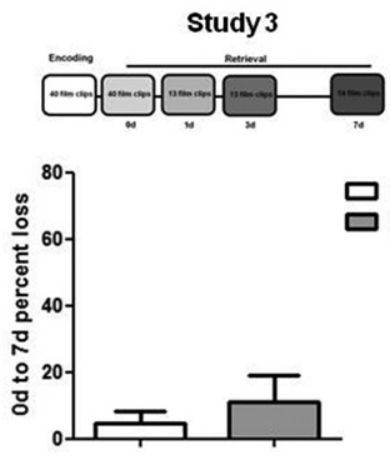

Figure 4. Percent of lost details between the immediate and 7-d retrieval for all three studies. Schematic of the experimental timeline, and the percentage of lost central and peripheral details between the immediate retrieval $(0 \mathrm{~d})$ and the 7 -d retrieval session for Study $1(A)$, Study $2(B)$, and Study 3 ( $C$ ).

appears that participants' subjective feelings of the quality of their memory may not be the most reliable indicator of memory content. This observation will be addressed in the Discussion section.

\section{Discussion}

Peripheral (perceptual) details that render a memory rich and vivid likely cannot be accessed easily in the absence of central details that define its core meaning or gist (Conway and Pleydell-Pearce 2000; Loveday and Conway 2011). These peripheral and central elements that together make up an episodic memory, however, are lost at different rates over time, with peripheral elements being much more susceptible to rapid decline. While this has been known for some time, (Thorndyke 1977; Rumelhart and Ortony 1977; Bahrick 1984; Conway et al. 1991), the goal of the present study was to relate a number of theoretical ideas concerning the influence of cuing and repeated retrieval on the differential rates of forgetting (or memory retention) for qualitatively different aspects of episodic memory, using a consistent, and ecologically valid, naturalistic memory task.

The results of Study 1 confirmed previous findings (Thorndyke 1977; Bahrick 1984; Conway et al. 1991) of differential forgetting of central and peripheral elements of an episodic memory over time, validating the memory paradigm used in the present studies. The results of Studies 2 and 3 demonstrate that this apparent forgetting of details over time may not be permanent or invariable, and highlight the use of cuing and repeated retrieval to promote episodic memory retention. It should be noted that the discussion is based on this objective measure of performance (the number of reported memory details), rather than subjective self-report ratings of memory quality. As these two measures (details and ratings) show different patterns of results, we will address this discrepancy later in the Discussion, and will try to reconcile the two sets of findings.

Although forgetting of details is typically interpreted as a loss-of-function, in certain situations, it may be adaptive to recall only minimal details from an event. Recalling every detail at each retrieval could overwhelm online cognitive resources (Hardt et al. 2013). At the same time, the ability to gain access to details of an episodic memory when appropriately cued may be valuable in situations where specificity is required, such as reinstating context during eye witness testimony (Krafka and Penrod 1985; Schacter et al. 2007; Buckner 2010; Sheldon et al. 2011; Furman et al. 2012; Szpunar et al. 2014).

\section{Recovering forgotten episodic details}

Memory decay and interference are among the main processes thought to mediate forgetting (for review, see Hardt et al. 2013; Sadeh et al. 2014). Regardless of the mechanism underlying forgetting in the present studies, the findings of Study 2 suggest that impoverished memory for the films may be due as much to inaccessibility, as to a long-term memory storage deficit, and that cues may be effective in accessing those forgotten details (Tulving and Pearlstone 1966; Tulving and Psotka 1971; Tulving 1972; Dudai 2004; Hardt et al. 2009; Loveday and Conway 2011). It has been shown that providing contextual cues can enhance memory retrieval, particularly during conditions involving high interference (Winocur and Kinsbourne 1978; Winocur et al. 1981). In a test of autobiographical episodic memory, providing a highly familiar landmark cue enhanced the retrieval of details for memories associated with the cued scene (Robin and Moscovitch 2014). Even in amnesic patients, cuing by placing patients in a relevant setting enhanced the retrieval of autobiographical memory details, both internal (i.e., episodic and perceptual details) and external (semantic details) elements, relative to memories retrieved in a control setting (Miles et al. 2013). This evidence suggests that appropriate real world contextual cues enhance the retrieval of naturalistic memories, in both healthy adults and those with memory impairments.

The reminder cues in Study 2 selectively enhanced retrieval of peripheral details, while having no significant effect on the retrieval of central story details. These more detailed attributes of the event are thought to be less accessible over time, possibly requiring more effortful retrieval, but may be elicited if given appropriate cues. In line with this idea, Hasher and Griffen (1978) proposed that recall of an event's general "theme" may be more accessible due to repeated and distributed presentations within the event. Therefore, in the absence of explicit cuing, details pertaining to the general theme will be most easily accessed during memory recall. It is possible that the reminders did not affect memory for the gist of the film clips because the generalized memory is less sensitive to cuing effects. Related to this, while the cues effectively restored some peripheral details at the longest delay, it was not a complete recovery, suggesting that some of the peripheral details are irretrievably forgotten. Given the loss of memory for peripheral details at the 3-d delay test, it is possible that the loss of those details is rapid, and while they may be available when retrieval is conducted immediately after encoding (0-d), within several days, these details are already forgotten. By 7-d, while there are still some details that cannot be recovered, there 
remains memory for other details that have been stored, but are not immediately accessible in the absence of appropriate cuing.

These explanations for the observed results are speculative. We acknowledge that future studies would be required to determine systematically the time point at which these details are lost. The effectiveness of a reminder in modifying a memory may relate not only to the type of memory representations, but also to the age of the memory, and the quality and duration of the reminder (Tronson and Taylor 2007; Schiller and Phelps 2011; Dudai 2012; Wichert et al. 2012, 2013; Forcato et al. 2013). In Study 2, we used a reminder that cued peripheral/perceptual details. Had we used centrally themed reminders (such as presenting a main plot point) there might have been a facilitation of retrieval for central details. Future research may determine whether forgotten central details require a qualitatively different cue to be accessed, or if once forgotten, they are permanently lost. Together, the present results suggest that cuing with a peripherally based cue alone is not sufficient to enhance the overall coherent retrieval of the memory. As a control condition in a pilot study, we found that the visual reminder cue and title alone is not sufficient to induce central and peripherally detailed reports in participants who had not previously seen the corresponding film clip (data not shown), suggesting that the reminder cue alone is not simply providing perceptual details, but rather serves to reactivate the detailed version of the episodic memory.

\section{Preventing the forgetting of details}

We have shown that cuing with reminders can reactivate a perceptually rich version of an episodic memory, suggesting that not all details are irretrievably lost. Instead, over time, they may become inaccessible. In Study 3, we showed that actively retrieving a memory immediately following encoding can facilitate retention of central and peripheral elements of an episode. This finding is consistent with the "testing effect", a phenomenon in which repeated, spaced retrieval (or self-testing) of newly learned material promotes long-term retention of information in a way that is far superior to using repeated-study sessions (Gates 1917; Spitzer 1939; Tulving 1967; Carrier and Pashler 1992; Roediger and Karpicke 2006; Karpicke and Roediger 2008; Rosburg et al. 2015). This phenomenon has been observed across several verbal (Wheeler et al. 2003; Carpenter and DeLosh 2006; Carpenter et al. 2006; Pyc and Rawson 2007; Karpicke and Roediger 2008; Toppino and Cohen 2009; Rowland and DeLosh 2014), nonverbal (Carpenter and Pashler 2007; Kang 2010), and semantic (Carpenter 2009; Veltre et al. 2014) memory domains. An important contribution of Study 3 is that, unlike using cues to enhance only the retrieval of peripheral elements (Study 2), repeated testing/retrieval can promote the retention and retrieval of both central and peripheral elements of naturalistic memories for complex episodes, complementing findings in which cued retrieval protects against subsequent loss of detailed memory for eyewitness testimony events (Pansky, 2012).

Studies on the testing effect suggest that elaboration, or the generation of additional memory traces, during retrieval may increase the likelihood that the memory trace will be accessible for future retrieval (Roediger and Butler 2011). This mnemonic benefit may be due to the effects of effortful retrieval (Gardiner et al. 1973; Bjork and Bjork 1992; Pyc and Rawson 2007), and/or semantic elaboration (Carpenter 2009, 2011). Although the precise mechanisms underlying the testing effect are not well understood, recent fMRI studies found that increased activity in the left inferior parietal lobe and middle temporal gyrus during repeated retrieval of word pairs (but not during passive restudying) predicted better subsequent recall (van den Broek et al. 2013). Repeated testing also enhanced functional connectivity between the hippo- campus, and the medial prefrontal and posterior cingulate cortex (Wing et al. 2013), all key regions within the recollection network (Rugg and Vilberg 2013). Increased activity in the anterior cingulate cortex during retrieval has been observed up to 5 mo following initial repeated retrieval sessions, suggesting that long-term mnemonic benefits from the testing effect may be partially due to enhanced systems-level memory consolidation (Eriksson et al. 2011).

Our results using reminders and repeated retrieval to strengthen memory details are consistent with the mounting evidence that memory consolidation is a dynamic process in which cuing or reactivating a previously encoded episodic memory may render it sensitive to updating or strengthening as the memory trace restabilizes (for review, see Tronson and Taylor 2007; Roediger and Butler, 2011; Schiller and Phelps 2011; Dudai 2012; Schwabe et al. 2014). While most previous studies have shown that reactivating a declarative memory can enhance subsequent retrieval, they typically use relatively simple stimuli, such as paired-associate syllables (Coccoz et al. 2011, 2013; Forcato et al. 2011, 2013). A recent study using more naturalistic stimuli has shown that reactivating memory of a museum tour enhanced later recognition memory for items on the tour (St-Jaques and Schacter 2013), whereas introducing interference following reactivation impairs subsequent recognition memory (Chan and LaPaglia 2013; St-Jaques and Schacter 2013).

To our knowledge, our study is the first to show the effectiveness of both reminders and repeated retrieval facilitating richly detailed memory for complex naturalistic episodes within the same memory paradigm. The mechanisms mediating the facilitation following cuing and repeated retrieval likely differ, in part, due to the different intervals between memory reactivation and subsequent recall. In Study 3, retrieving all clips immediately after encoding prevented time-dependent loss of both central and peripheral details. It should be noted that central details were retained at a proportionately higher level than peripheral details even in the absence of reminders or repeated retrieval (Study 1 and 2), so it remains unclear if the repeated retrieval strengthens both types of detail to the same degree. A recent study found that testing of object-name pairs enhanced subsequent itemsource memory, and led to increased ERP activity in the left parietal lobe, (Rosburg et al. 2015), a putative neural correlate for recollection-based retrieval (Yonelinas et al. 2005; Vilberg and Rugg 2009; Addante et al. 2012). This suggests that repeated test$\mathrm{ing} /$ retrieval is associated with increased recollection (reinstantiation of the context and details related to an event), as opposed to familiarity (recall without contextual or other related details), at the time of retrieval (Yonelinas 2002). Thus, it is possible that multiple testing and/or retrieval sessions are effective at strengthening memory because recollection-based retrieval reactivates both central and peripheral elements, which together enhance the overall quality of a memory, whereas partially cuing the same memory with a perceptual cue only enhances the retrieval of those details.

\section{Feelings of forgetting}

In the present studies, subjective memory ratings for story content and vividness of perceptual detail did not always correspond to the objective detail scoring from the verbal retrieval sessions, suggesting that an individual's confidence in the quality or vividness of his or her memory is not, on its own, a reliable measure of the objective aspects and/or veridical quality of a memory (Loftus 1979; Tulving 1981; Qin et al. 2011; Johnson et al. 2015). Despite a linear decline in the self-report ratings for both the story content and the perceptual content of the memories, suggesting an overall feeling of forgetting, participants consistently rated 
their memory for the story content more highly than their memory for the accompanying perceptual content. This is in line with the idea that central, or gist-like elements of a memory tend to be retained better than peripheral elements (Thorndyke 1977; Bahrick 1984; Conway et al. 1991). Despite the memory enhancing or protective effects of cuing or repeated retrieval seen in the objective detail scoring of memory content, participants still reported a time-dependent decline in the subjective content and vividness of their memories. These two effects may not be contradictory as it is possible that one's perceived ability to retrieve a memory vividly might decline before retrieval itself declines. For example, one's subjective ratings may be influenced by the effort it takes to retrieve the information, with greater effort being associated with greater uncertainly which, in turn, may lead to a lower subjective rating (Koriat 2000). Alternatively, there may indeed be some decline in objective memory which our tests are not sensitive enough to detect. The self-report memory ratings for story content and perceptual details tended to correlate highly across all studies and delays, (see Supplemental Table S1). It may be that rating the overall story content of the memory subsequently influenced the rating of the associated perceptual content. This idea that the initial retrieval of the central story elements influences subsequent retrieval of the peripheral details will be discussed below.

\section{Theories of detailed forgetting}

While our studies were not designed as a direct test of any specific theory of memory consolidation, the results are in line with certain prevailing ideas in cognitive psychology and neurobiology. Among the former, one of the more relevant is fuzzy trace theory (FTT) which asserts that the degree to which verbatim traces (precise, contextually detailed representation of the memory) or gist traces (general, fuzzy, semantic representation of the memory) are used to recall a memory may influence the degree to which memories are forgotten (Brainerd and Reyna 1993, 1998; Reyna and Brainerd 1995). According to this view, adults typically rely on a "fuzzy processing preference", in which primarily the gist elements are used to make a decision about a previously experienced event (Brainerd and Reyna 2002). In the present studies, this fuzzy processing preference may have been the default retrieval strategy; however, during the retrieval session, participants were explicitly prompted to retrieve all the perceptual details from their memory following the prompt to retrieve the central story details. According to FTT, it is possible that the verbatim traces, (comparable with our peripheral details) are available, but inaccessible by default, unless the participant is directly prompted to retrieve them. The results of Study 2 suggest that this may be the case. In the absence of a "reminder cue", the peripheral details may be inaccessible. While there may still be some forgetting over time, in which case the details are not merely inaccessible, but entirely lost (as suggested by the time-dependent forgetting of peripheral details in Study 1, and in the nonreminded condition of Study 2), it is also likely that some of the peripheral details are inaccessible, but may be effortfully retrieved if given appropriate cues (i.e., a screenshot reminder, as well as explicit prompting to retrieve those perceptual details).

Our findings are also in line with the trace transformation theory (TTT) of memory consolidation (Winocur et al. 2010; Winocur and Moscovitch 2011), which proposes that, initially, episodic memory is comprised of both central and peripheral details (and thought to be mediated by the hippocampus). According to this view, over time a gist-like version of this memory develops in which only the central schematic elements are retained (thought to be represented in extra-hippocampal cortical regions). Although peripheral details may degrade over time, the detailed version of an episodic memory remains dependent on the hippocampus. Critically, TTT holds that, even in the healthy brain, both general and detailed memory traces can coexist, (Winocur and Moscovitch 2011), with the cues, or task demands, at the time of retrieval influencing which version will be recovered. Our results suggest that, for older memories, the generalized version may dominate, and be retrieved more readily. Further, since details may be recovered with appropriate cuing, their apparent loss appears to be due, at least in part, to a retrieval failure, perhaps resulting from a weakening of synaptic connections of the memory trace which may be reengaged to support detailed memory retrieval (Goshen et al. 2011; Tonegawa et al. 2015).

\section{Conclusion}

Together, the results of the three studies suggest that a detailed episodic memory and a more general gist-like version of that same event can coexist, but they are differentially sensitive to forgetting over time. With the better retention of memory for central details (gist), but a steeper time-dependent decline in memory for the peripheral elements (Study 1), it is possible that the memory for the gist of the episode may provide a general framework to support the reconstruction of a detailed and rich episodic memory (Conway et al. 2009). This central framework might be especially critical when memories are effortfully retrieved, rather than spontaneously retrieved. While this was not directly tested in the current study, it would be an interesting avenue for further research. In the absence of a cue for the central details, cuing the periphery alone (Study 2) may be effective in enhancing the retrieval of peripheral details. Finally, our results suggest that repeated effortful retrieval is effective in strengthening both central and peripheral elements of memory (Study 3), increasing the likelihood that both types of details will be accessed during subsequent retrieval, thereby extending the range of the "testing effect" to naturalistic events.

\section{Materials and Methods}

\section{Subjects}

Participants between the ages of 18-35 were recruited from the University of Toronto's Psychology 100 subject pool and through advertisements on campus. Participants were reimbursed $\$ 10$ per hour. All procedures were approved by the University of Toronto's Research Ethics Board, and conducted in accordance with the guidelines set by the Tri-Council Policy Statement: Ethical Conduct for Research Involving Humans. All participants gave written informed consent and were fluent in English, with no history of psychiatric or neurological disorders. See Table 1 for a description of the participants included in each experiment.

\section{Materials}

\section{Film clip stimuli}

Forty film clips were used to test episodic memory. Clips were $23 \mathrm{sec}$ in duration, taken from foreign films, with limited dialog (some of these clips were used in a previous study; St-Laurent et al. 2014). Each clip was analyzed for its content based on four feature categories: visual complexity (colour, background complexity, movement, number of frame transitions, number of background characters), story complexity (number of central characters, storyline complexity), sound complexity (speech, music, background noise), and emotional content (funny, surprising, cute, sad, quirky). Three scorers (M.J.S., K.B., M.S.L.) independently rated each clip on each criterion, and assigned a score between 1 (low) and 5 (high), or a yes/no rating. Composite scores for each category were averaged, and mean scores were transformed to $z$-scores. Each clip's Z-scores were used to divide the 40 clips into 
Table 1. Participant demographics

\begin{tabular}{|c|c|c|c|c|}
\hline Study & $n$ & Age & $\begin{array}{l}\operatorname{Sex} \\
(\mathrm{M} / \mathrm{F})\end{array}$ & Notes \\
\hline 1 & 11 & 21.6 & $5 / 6$ & $\begin{array}{l}\text { Data recording failed for two } \\
\text { participants' 3-d session and 7-d } \\
\text { session; one participant did not } \\
\text { perform the 7-d session. }{ }^{a}\end{array}$ \\
\hline 2 & 20 & 20.7 & $7 / 13$ & $\begin{array}{l}\text { Data recording failed for two } \\
\text { participants' 0-d session; two } \\
\text { participants did not perform the 3-d } \\
\text { session, and one did not perform the } \\
\text { 7-d session. }{ }^{\mathrm{a}}\end{array}$ \\
\hline 3 & 11 & 22.9 & $6 / 5$ & $\begin{array}{l}\text { One participant did not perform the } 3-d \\
\text { session. }{ }^{a}\end{array}$ \\
\hline
\end{tabular}

a Participants with missing data were excluded from statistical analyses. The degrees of freedom in the different analyses vary due to missing data points in various conditions (see Supplemental Results).

three evenly distributed series of 13 or 14 clips, balanced across the four categories (see Supplemental Fig. S1). For each participant, each of the three series was pseudorandomly assigned to be tested at one of the delays used in the memory retrieval sessions.

\section{Procedure}

Procedures followed were based on those developed for a previous study (St-Laurent et al. 2014). All experiments were conducted on a desktop computer using E-Prime 2 (version 2.0.10.242, E-Studio, Psychology Software Tools Inc.), in a sound-attenuated room. Participants were read a set of instructions, and then performed a practice session in which they watched two sample clips and performed the memory retrieval task to ensure they understood the test procedures. Participants were told they would be subsequently tested on their memory for the clips following varying delays, and instructed not to rehearse the information in the interim.

\section{Encoding session}

During encoding, participants viewed the 40 film clips, presented in randomized order. Each clip was given a title (e.g., "Boy, Girl, and Balloon") that served as a retrieval cue in the retrieval session of the experiment. The title appeared centrally on the screen for 2 sec immediately before and after the clip played. Clips were centrally presented on a computer screen, with sound delivered though computer speakers. Participants were instructed to pay attention to the title and content of each clip. A fixation cross was presented for 2 sec between each clip. Participants were given a short self-timed break between every 10 clips. For all three studies, all clips were encoded within a single session; series of clips (see Film Clip Stimuli) were then retrieved at different time points. Series were assigned pseudorandomly to a retrieval session time point in a manner that was counterbalanced across participants.

\section{Retrieval session}

For the retrieval session in each experiment, participants were presented with the title of a clip for $16 \mathrm{sec}$, during which they were instructed to visualize the clip in their mind, from beginning to end. Next, they used a key pad to rate how well they recalled the clip's story content, on a scale of 1 (low) to 5 (high). Story content refers to the general plot line of the story ("what happened"), and events central to the progression of the episode (Berntsen 2002; St-Laurent et al. 2014). A rating of 1 indicated there was no story content in their memory, while 5 indicated they felt that their memory contained all of the story elements. Next, participants rated the vividness of their memory's perceptual content during the retrieval period in a similar way. Perceptual content referred to visual (colors, lighting, textures, facial features, clothing, positions of objects, background details, weather, lighting conditions, etc.) and auditory (talking, laughing, background music, street sounds) details. Immediately following the ratings of each clip, participants were asked to verbally report the story content details they could recall from the clip (what happened, who did what, what was the situation; they were given a maximum of 60 sec to report these details). Finally, participants were asked to verbally report any perceptual (visual or auditory) details they imagined in their mind's eye while they recalled the clip (for up to 60 sec). Recordings of verbal responses were transcribed and scored according to a system described below. The presentation order of clips was randomized within each retrieval session. See Figure $5 \mathrm{~A}$ for schematic of the encoding and retrieval sessions.

Study 1: Memory testing occurred across three sessions. Clips were divided into three series of 13 or 14 clips (see above). Each series of clips was tested immediately (several minutes, $0 \mathrm{~d}$ ), or following a 3- or 7-d delay after encoding. In this way, memory for each clip was tested only once. See Figure 1A for a schematic of the design for Study 1.

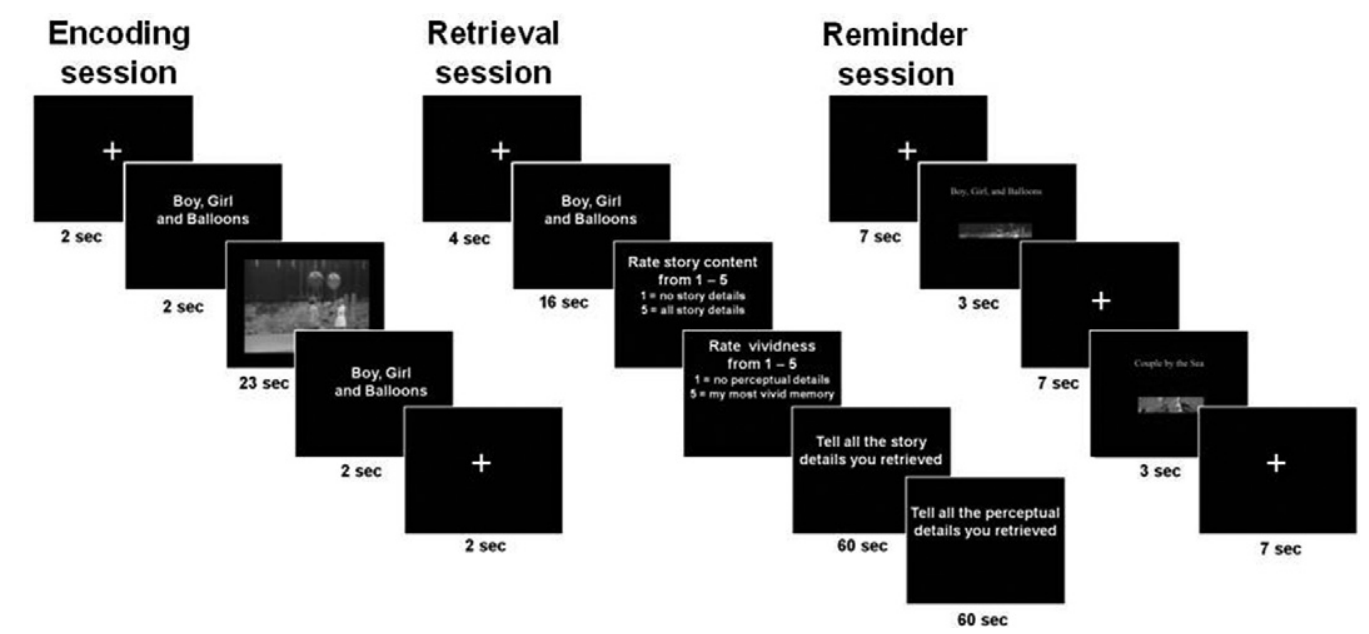

Figure 5. Schematics of study design. Schematic of the study design for the encoding session, retrieval session, and reminder session. Encoding session: 40 film clips were shown to participants in a randomized order. Retrieval session: The retrieval sessions were identically run across all delays (0-, 1-, 3-, 7-d), and all studies. Reminder session: The reminder session was run immediately preceding the retrieval session for the 3- and 7-d delay tests in Study 2. 
Table 2 Mean number of errors per study (standard error)

\begin{tabular}{|c|c|c|c|c|c|c|}
\hline & \multicolumn{6}{|c|}{ Delay Condition } \\
\hline & $0 \mathrm{~d}$ & $1 \mathrm{~d}$ & $3 d$ & $3 \mathrm{~d} R$ & $7 d$ & $7 \mathrm{~d} R$ \\
\hline \multicolumn{7}{|l|}{ Study 1} \\
\hline Central error & $0.03(0.01)$ & $\mathrm{n} / \mathrm{a}$ & $0.05(0.03)$ & $\mathrm{n} / \mathrm{a}$ & $0.15(0.07)$ & $\mathrm{n} / \mathrm{a}$ \\
\hline Peripheral error & $0.83(0.12)$ & $n / a$ & $1.41(0.15)$ & $n / a$ & $1.50(0.18)$ & $n / a$ \\
\hline \multicolumn{7}{|l|}{ Study 2} \\
\hline Central error & $0.15(0.04)$ & $\mathrm{n} / \mathrm{a}$ & $0.31(0.08)$ & $0.27(0.07)$ & $0.36(0.11)$ & $0.51(0.14)$ \\
\hline Peripheral error & $1.52(0.21)$ & $\mathrm{n} / \mathrm{a}$ & $1.53(0.26)$ & $1.61(0.27)$ & $1.47(0.25)$ & $1.59(0.27)$ \\
\hline \multicolumn{7}{|l|}{ Study 3} \\
\hline Central error & $0.08(0.02)$ & $0.12(0.04)$ & $0.10(0.03)$ & $\mathrm{n} / \mathrm{a}$ & $0.12(0.04)$ & $\mathrm{n} / \mathrm{a}$ \\
\hline Peripheral error & $0.87(0.07)$ & $1.11(0.10)$ & $1.09(0.15)$ & $\mathrm{n} / \mathrm{a}$ & $1.19(0.16)$ & $n / a$ \\
\hline
\end{tabular}

Errors were details reported that did not match the actions and details in the film clip. The total number of errors was subtracted from the total number of accurately recalled details to generate the corrected central and peripheral detail score for each film clip (Retrieval Success).

Study 2: Memory testing was identical to the procedures reported in Study 1, except that participants received a reminder session just prior to the 3- and 7-d delay retrieval sessions. During this reminder session, participants were shown the clip title and a 1-inch high horizontal strip taken from a screenshot of the clip (Fig. 5). A horizontal strip was selected so that no coherent information about the scene would be available making the cue as purely perceptual as possible. In addition, a Gaussian blur mask was filtered over the screen-shot using Image J software (NIH) to partially obscure the visual details in the reminder. Reminder cues were presented on the computer screen for $3 \mathrm{sec}$, followed by a fixation-cross for a $7 \mathrm{sec}$ inter-trial interval. Reminders were only given for half of the clips to be tested in the subsequent memory retrieval session (reminded, R). The other half of clips tested during the retrieval session did not receive a reminder prior to retrieval (nonreminded, NR), which allowed us to determine the effectiveness of the reminder in reinstating memory details for the clips during the subsequent memory retrieval session. The retrieval session immediately followed the reminder session for the 3 - and 7-d tests. No reminders were given for clips tested immediately after encoding $(0 \mathrm{~d})$. See Figure $2 \mathrm{~A}$ for a schematic of the design for Study 2.

Study 3: Memory retrieval occurred across four sessions. Immediately following encoding, memory for all 40 clips was tested (immediate retrieval, $0 \mathrm{~d}$ ). Each series of 13 or 14 clips was then retested following either a 1-, 3-, or 7-d delay. Retrieval was conducted identically to the procedures reported in Study 1 . See Figure 3A for a schematic of the design for Study 3.

\section{Scoring and data analysis}

Self-report ratings of story and perceptual content were averaged across clips for each delay. As described above, two separate recordings of the verbal retrieval responses were obtained for each clip to encourage participants to report what they recalled about a clip's storyline and perceptual content. The recordings were manually transcribed and responses were coded and scored using a modified version of the Autobiographical Interview (Berntsen 2002; Levine et al. 2002), to categorize central story details and peripheral details (see Supplemental Fig. S2 for an example of a cod- ed transcript). Central story details were elements that could not be modified or omitted without changing the plotline of the story (Berntsen 2002). In order to score central details consistently, 5-6 central story points were identified for each clip and recorded as a "central narrative" (see Supplemental Methods for list of central details per clip). These central story points were identified based on narratives used in a previous study (St-Laurent et al. 2014), modified on the basis of data from a pilot version of this task. A participant was given a score of one central point for each detail they retrieved that corresponded to a point in the central narrative for that clip. Peripheral details were considered any additional descriptive information, including perceptual, emotional, and contextual details present in the film clip. One peripheral point was scored for each peripheral story detail reported during the verbal retrieval session (see Supplemental Fig. S2). Notably, there was an upper limit to the number of central points a participant could score, but no such limit for peripheral points (see Supplemental Methods; Supplemental Fig. S1a). To control for the different baselines of each detail type (central and peripheral), additional analyses were performed for each study. We conducted planned comparisons $t$-tests investigating the percentage of details lost (i.e., percent loss $=[1-(7 \mathrm{~d} / 0 \mathrm{~d})] \times 100)$ between the immediate retrieval test $(0 \mathrm{~d})$ and the 7 -d retrieval test $(7 \mathrm{~d})$, to confirm that any observed differences in rates of forgetting were not due to such differences in baseline numbers of details.

For each clip, both central and peripheral details were coded and tallied across the first recording (participant probed for story content) and second recording (participant probed for perceptual details) by an experimenter (S.P.) blind to the delay or reminder condition. Each reported detail was classified as either central or peripheral. No additional points were assigned for repeated details, or for unrelated information about the film clips (i.e., opinions or speculations). Errors in central and peripheral details were also calculated. Errors were considered any recalled details that did not match the information presented in the film clip. For each type of detail (central or peripheral), the total number of errors was subtracted from the total number of correct details (i.e., Retrieval Success = \# correct details - \# errors) to determine the corrected memory retrieval success scores used in the final data analyses. For each participant, the corrected central and

Table 3. Mean number of failed trials per study (standard error)

\begin{tabular}{lcccccc}
\hline & \multicolumn{5}{c}{ Delay Condition } \\
\cline { 2 - 6 } & $\mathbf{0 ~ d}$ & $\mathbf{1} \mathbf{d}$ & $\mathbf{3 ~ d}$ & $\mathbf{3 ~ d ~ R}$ & $\mathbf{7 ~ d ~}$ \\
\hline Study 1 & $0.18(0.12)$ & $\mathrm{n} / \mathrm{a}$ & $2.33(0.58)$ & $\mathrm{n} / \mathrm{a}$ & $3.75(0.82)$ & $\mathbf{7 ~ d ~ R}$ \\
Study 2 & $0.22(0.10)$ & $\mathrm{n} / \mathrm{a}$ & $0.63(0.16)$ & $0.66(0.16)$ & $2.21(0.29)$ & $0.74(0.23)$ \\
Study 3 & $1.36(0.72)$ & $0.45(0.28)$ & $0.45(0.25)$ & $\mathrm{n} / \mathrm{a}$ & $0.82(0.40)$ & $\mathrm{n} / \mathrm{a}$ \\
\hline
\end{tabular}

Failed trials were trials assigned self-report memory ratings of 1 , and trials with zero central and peripheral details reported. These trials were excluded from data analyses. 
peripheral details were averaged across all clips for each delay condition $(0-, 1-, 3-$, and $7-d)$. The mean errors in each study are presented in Table 2.

For all analyses, we excluded "failed" retrieval trials, which were trials given memory retrieval ratings of " 1 " (indicating low memory for story content and low vividness of perceptual details) and for which there were no central or peripheral details reported during the verbal retrieval session (see Table 3 for details of failed trials per participant in each study). We also excluded trials in which the participant reported details corresponding to the wrong film clip. Although these data were excluded in the analyses described below, analyses performed with these data included produced equivalent results. All main analyses were conducted as repeated-measures ANOVAs, and all post hoc analyses, unless otherwise indicated, were conducted as Bonferroni-corrected $t$-tests. Data analysis was performed using SPSS22.

\section{Acknowledgments}

We gratefully acknowledge the technical assistance of Nick Hoang and Christa Dang, and we thank the two anonymous reviewers for their comments on an earlier version of this paper. This work was supported by a Canadian Institutes of Health Research (CIHR) grant (MOP 125958) to M.M., G.W., C.G. M.J.S. was supported by a CIHR post-doctoral fellowship. K.B. was supported by a Natural Sciences and Engineering Research Council of Canada (NSERC) doctoral award.

\section{References}

Addante RJ, Ranganath C, Yonelinas AP. 2012. Examining ERP correlates of recognition memory: evidence of accurate source recognition without recollection. Neuroimage 62: 439-450.

Anderson SJ, Conway MA. 1993. Investigating the structure of autobiographical memories. J Exp Psychol Learn Mem Cogn 19: 1178-1196.

Bahrick HP. 1984. Semantic memory content in permastore: fifty years of memory for Spanish learned in school. J Exp Psychol Gen 113: 1-29.

Berntsen D. 2002. Tunnel memories for autobiographical events: central details are remembered more frequently from shocking than from happy experiences. Mem Cognit 30: 1010-1020.

Bjork RA, Bjork EL. 1992. A new theory of disuse and an old theory of stimulus fluctuation. From learning processes to cognitive processes: essays in honor of William K. Estes, Vol. 2, pp. 35-67.

Brainerd CJ, Reyna VF. 1993. Memory independence and memory interference in cognitive development. Psychol Rev 100: 42-67.

Brainerd CJ, Reyna VF. 1998. Fuzzy-trace theory and children's false memories. J Exp Child Psychol 71: 81-129.

Brainerd CJ, Reyna VF. 2002. Fuzzy-trace theory and false memory. Curr Dir Psychol Sci 11: 164-169.

Brewer WF, Pani JR. 1996. Reports of mental imagery in retrieval from long-term memory. Conscious Cogn 5: 265-287.

Buckner RL. 2010. The role of the hippocampus in prediction and imagination. Annu Rev Psychol 61: 27-48, C21-C28.

Carpenter SK. 2009. Cue strength as a moderator of the testing effect: the benefits of elaborative retrieval. J Exp Psychol Learn Mem Cogn 35: $1563-1569$.

Carpenter SK. 2011. Semantic information activated during retrieval contributes to later retention: support for the mediator effectiveness hypothesis of the testing effect. J Exp Psychol Learn Mem Cogn 37: 1547-1552.

Carpenter SK, DeLosh EL. 2006. Impoverished cue support enhances subsequent retention: support for the elaborative retrieval explanation of the testing effect. Mem Cognit 34: 268-276.

Carpenter SK, Pashler H. 2007. Testing beyond words: using tests to enhance visuospatial map learning. Psychon Bull Rev 14: 474-478.

Carpenter SK, Pashler H, Vul E. 2006. What types of learning are enhanced by a cued recall test? Psychon Bull Rev 13: 826-830.

Carrier M, Pashler H. 1992. The influence of retrieval on retention. Mem Cognit 20: 633-642.

Chan JC, LaPaglia JA. 2013. Impairing existing declarative memory in humans by disrupting reconsolidation. Proc Natl Acad Sci 110: 9309-9313.

Coccoz V, Maldonado H, Delorenzi A. 2011. The enhancement of reconsolidation with a naturalistic mild stressor improves the expression of a declarative memory in humans. Neuroscience 185: $61-72$.
Coccoz V, Sandoval AV, Stehberg J, Delorenzi A. 2013. The temporal dynamics of enhancing a human declarative memory during reconsolidation. Neuroscience 246: 397-408.

Conway MA, Pleydell-Pearce CW. 2000. The construction of autobiographical memories in the self-memory system. Psychol Rev 107: $261-288$.

Conway MA, Cohen G, Stanhope N. 1991. On the very long-term retention of knowledge acquired through formal education: twelve years of cognitive psychology. J Exp Psychol Gen 120: 395-409.

Conway ARA, Skitka LJ, Hemmerich JA, Kershaw TC. 2009. Flashbulb memory for 11 September 2001. Appl Cogn Psychol 23: 605-623.

Dudai Y. 2004. The neurobiology of consolidations, or, how stable is the engram? Annu Rev Psychol 55: 51-86.

Dudai Y. 2012. The restless engram: consolidations never end. Annu Rev Neurosci 35: 227-247.

Eriksson J, Kalpouzos G, Nyberg L. 2011. Rewiring the brain with repeated retrieval: a parametric fMRI study of the testing effect. Neurosci Lett 505: 36-40.

Forcato C, Rodriguez ML, Pedreira ME. 2011. Repeated labilization-reconsolidation processes strengthen declarative memory in humans. PLoS One 6: e23305.

Forcato C, Fernandez RS, Pedreira ME. 2013. The role and dynamic of strengthening in the reconsolidation process in a human declarative memory: what decides the fate of recent and older memories? PLoS One 8: e61688.

Furman O, Dorfman N, Hasson U, Davachi L, Dudai Y. 2007. They saw a movie: long-term memory for an extended audiovisual narrative. Learn Mem 14: $457-467$

Furman O, Mendelsohn A, Dudai Y. 2012. The episodic engram transformed: time reduces retrieval-related brain activity but correlates it with memory accuracy. Learn Mem 19: 575-587.

Gardiner FM, Craik FI, Bleasdale FA. 1973. Retrieval difficulty and subsequent recall. Mem Cognit 1: 213-216.

Gates AI. 1917. Recitation as a factor in memorizing. Arch Psychol 6: 1-104.

Gilboa A, Winocur G, Rosenbaum RS, Poreh A, Gao F, Black SE, Westmacott R, Moscovitch M. 2006. Hippocampal contributions to recollection in retrograde and anterograde amnesia. Hippocampus 16: 966-980.

Goshen I, Brodsky M, Prakash R, Wallace J, Gradinaru V, Ramakrishnan C, Deisseroth K. 2011. Dynamics of retrieval strategies for remote memories. Cell 147: 678-689.

Hardt O, Wang SH, Nader K. 2009. Storage or retrieval deficit: the yin and yang of amnesia. Learn Mem 16: 224-230.

Hardt O, Nader K, Nadel L. 2013. Decay happens: the role of active forgetting in memory. Trends Cogn Sci 17: 111-120.

Hasher L, Griffen M. 1978. Reconstructive and reproductive processes in memory. J Exp Psychol Human Learn Mem 4: 318-330.

Hasson U, Furman O, Clark D, Dudai Y, Davachi L. 2008. Enhanced intersubject correlations during movie viewing correlate with successful episodic encoding. Neuron 57: 452-462.

Howard MW, Kahana MJ. 2002. A distributed representation of temporal context. J Mathl Psych 46: 269-299.

Johnson MK, Kuhl BA, Mitchell KJ, Ankudowich E, Durbin KA. 2015. Age-related differences in the neural basis of the subjective vividness of memories: evidence from multivoxel pattern classification. Cogn Affect Behav Neurosci 15: 644-661.

Kang SH. 2010. Enhancing visuospatial learning: the benefit of retrieval practice. Mem Cognit 38: 1009-1017.

Karpicke JD, Roediger HL III. 2008. The critical importance of retrieval for learning. Science 319: 966-968.

Keppel G, Underwood BJ. 1962. Proactive inhibition in short-term retention of single items. J Verb Learn Verb Behav 1: 153-161.

Koriat A. 2000. The feeling of knowing: some metatheoretical implications for consciousness and control. Consciou Cogn 9(2 Pt 1): 149-171.

Krafka C, Penrod S. 1985. Reinstatement of context in a field experiment on eyewitness identification. J Pers Soc Psychol 49: 58-69.

Levine B, Svoboda E, Hay JF, Winocur G, Moscovitch M. 2002. Aging and autobiographical memory: dissociating episodic from semantic retrieval. Psychol Aging 17: 677-689.

Loftus E. 1979. Eyewitness reliability. Science 205: 386-387.

Loveday C, Conway MA. 2011. Using SenseCam with an amnesic patient: accessing inaccessible everyday memories. Memory 19: 697-704.

Mendelsohn A, Furman O, Dudai Y. 2010. Signatures of Memory: brain coactivations during retrieval distinguish correct from incorrect recollection. Front Behav Neurosci 4: 18.

Miles AN, Fischer-Mogensen L, Nielsen NH, Hermansen S, Berntsen D. 2013. Turning back the hands of time: autobiographical memories in dementia cued by a museum setting. Conscious Cogn 22: 1074-1081.

Pansky A. 2012. Inoculation against forgetting: advantages of immediate versus delayed initial testing due to superior verbatim accessibility. $J$ Exp Psychol Learn Mem Cogn 38: 1792-1800. 
Pyc MA, Rawson KA. 2007. Examining the efficiency of schedules of distributed retrieval practice. Mem Cognit 35: 1917-1927.

Qin S, van Marle HJ, Hermans EJ, Fernandez G. 2011. Subjective sense of memory strength and the objective amount of information accurately remembered are related to distinct neural correlates at encoding. $J$ Neurosci 31: 8920-8927.

Reyna VF, Brainerd CJ. 1995. Fuzzy-trace theory: an interim synthesis. Learn Individ Differ 7: 1-75.

Robin J, Moscovitch M. 2014. The effects of spatial contextual familiarity on remembered scenes, episodic memories, and imagined future events. J Exp Psychol Learn Mem Cogn 40: 459-475.

Roediger HL, Karpicke JD. 2006. Test-enhanced learning: taking memory tests improves long-term retention. Psychol Sci 17: 249-e.

Roediger HL III, Butler AC. 2011. The critical role of retrieval practice in long-term retention. Trends Cogn Sci 15: 20-27.

Rosburg T, Johansson M, Weigl M, Mecklinger A. 2015. How does testing affect retrieval-related processes? An event-related potential (ERP) study on the short-term effects of repeated retrieval. Cogn Affect Behav Neurosci 15: 195-210.

Rosenbaum RS, Köhler S, Schacter DL, Moscovitch M, Westmacott R, Black SE, Gao F, Tulving E. 2005. The case of K.C.: contributions of a memory-impaired person to memory theory. Neuropsychologia 43: 989-1021.

Rowland CA. 2014. The effect of testing versus restudy on retention: a meta-analytic review of the testing effect. Psychol Bull 140: 1432-1463.

Rowland CA, DeLosh EL. 2014. Benefits of testing for nontested information: retrieval-induced facilitation of episodically bound material. Psychon Bull Rev 21: 1516-1523.

Rugg MD, Vilberg KL. 2013. Brain networks underlying episodic memory retrieval. Curr Opin Neurobiol 23: 255-260.

Rumelhart DE, Ortony A. 1977. The representation of knowledge in memory' In Schooling and the Acquisition of Knowledge (ed. Anderson RC, Spiro RJ, Montague WE). Lawrence Erlbaum, Hillsdale, NJ.

Ryan TJ, Roy DS, Pignatelli M, Arons A, Tonegawa S. 2015. Engram cells retain memory under retrograde amnesia. Science 348: 1007-1013.

Sadeh T, Ozubko JD, Winocur G, Moscovitch M. 2014. How we forget may depend on how we remember. Trends Cogn Sci 18: 26-36.

Schacter DL, Addis DR, Buckner RL. 2007. Remembering the past to imagine the future: the prospective brain. Nat Rev Neurosci 8: 657-661.

Schiller D, Phelps EA. 2011. Does reconsolidation occur in humans? Front Behav Neurosci 5: 24.

Schwabe L, Nader K, Pruessner JC. 2014. Reconsolidation of human memory: brain mechanisms and clinical relevance. Biol Psychiatry 76: 274-280.

Sheldon S, McAndrews MP, Moscovitch M. 2011. Episodic memory processes mediated by the medial temporal lobes contribute to open-ended problem solving. Neuropsychologia 49: 2439-2447.

Spitzer HF. 1939. Studies in retention. JEduc Psychol 30: 641-656.

Steinvorth S, Levine B, Corkin S. 2005. Medial temporal lobe structures are needed to re-experience remote autobiographical memories: evidence from H.M. and W.R. Neuropsychologia 43: 479-496.

St-Jacques PL, Schacter DL. 2013. Modifying memory: selectively enhancing and updating personal memories for a museum tour by reactivating them. Psychol Sci 24: 537-543.

St-Laurent M, Moscovitch M, Levine B, McAndrews MP. 2009. Determinants of autobiographical memory in patients with unilateral temporal lobe epilepsy or excisions. Neuropsychologia 47: 2211-2221.

St-Laurent M, Moscovitch M, Jadd R, McAndrews MP. 2014. The perceptual richness of complex memory episodes is compromised by medial temporal lobe damage. Hippocampus 24: 560-576.

Szpunar KK, Spreng RN, Schacter DL. 2014. A taxonomy of prospection: introducing an organizational framework for future-oriented cognition. Proc Natl Acad Sci 111: 18414-18421.
Thorndike EL. 1913. Educational Psychology (Vol. 2). Teacher's College, Columbia University, New York.

Thorndyke PW. 1977. Cognitive structures in comprehension and memory of narrative discourse. Cogn Psychol 9: 77-110.

Tonegawa S, Pignatelli M, Roy DS, Ryan TJ. 2015. Memory engram storage and retrieval. Curr Opin Neurobiol 35: 101-109.

Toppino TC, Cohen MS. 2009. The testing effect and the retention interval: questions and answers. Exp Psychol 56: 252-257.

Tronson NC, Taylor JR. 2007. Molecular mechanisms of memory reconsolidation. Nat Rev Neurosci 8: 262-275.

Tulving E. 1967. The effects of presentation and recall of material in free-recall learning. J Verb Learn Verb Behav 6: 175-184.

Tulving E. 1972. Episodic and semantic memory 1. In Organization of memory (ed. Tulving E, Donaldson W), pp. 381-403. Academic Press, New York.

Tulving E. 1981. Similarity relations in recognition. J Verb Learn Verb Behav 20: $479-496$

Tulving E. 1983. Elements of episodic memory. Behav Brain Sci 7: 223-268.

Tulving E, Pearlstone Z. 1966. Availability versus accessibility of information in memory for words. J Verb Learn Verb Behav 5: 381-391.

Tulving E, Psotka J. 1971. Retroactive inhibition in free recall: inaccessibility of information available in the memory store. J Exp Psychol 87: 1-8.

van den Broek GS, Takashima A, Segers E, Fernández G, Verhoeven L. 2013. Neural correlates of testing effects in vocabulary learning. Neuroimage 78: $94-102$.

Veltre MT, Cho KW, Neely JH. 2014. Transfer-appropriate processing in the testing effect. Memory 23: 1229-1237.

Vilberg KL, Rugg MD. 2009. Functional significance of retrieval-related activity in lateral parietal cortex: evidence from fMRI and ERPs. Hum Brain Mapp 30: 1490-1501.

Wheeler MA, Ewers M, Buonanno JF. 2003. Different rates of forgetting following study versus test trials. Memory 11: 571-580.

Wichert S, Wolf OT, Schwabe L. 2012. Changing memories after reactivation: a one-time opportunity? Neurobiol Learn Mem 99: 38-49.

Wichert S, Wolf OT, Schwabe L. 2013. Updating of episodic memories depends on the strength of new learning after memory reactivation. Behav Neurosci 127: 331-338.

Wing EA, Marsh EJ, Cabeza R. 2013. Neural correlates of retrieval-based memory enhancement: an fMRI study of the testing effect. Neuropsychologia 51: 2360-2370.

Winocur G, Kinsbourne M. 1978. Contextual cueing as an aid to Korsakoff amnesics. Neuropsychologia 16: 671-682.

Winocur G, Moscovitch M. 2011. Memory transformation and systems consolidation. J Int Neuropsychol Soc 17: 766-780.

Winocur G, Kinsbourne M, Moscovitch M. 1981. The effect of cuing on release from proactive interference in Korsakoff amnesic patients. J Exp Psychol Human Learn Mem 7: 56-65.

Winocur G, Moscovitch M, Bontempi B. 2010. Memory formation and long-term retention in humans and animals: convergence towards a transformation account of hippocampal-neocortical interactions. Neuropsychologia 48: 2339-2356.

Yonelinas AP. 2002. The nature of recollection and familiarity: a review of 30 years of research. J Mem Lang 46: 441-517.

Yonelinas AP, Otten LJ, Shaw KN, Rugg MD. 2005. Separating the brain regions involved in recollection and familiarity in recognition memory. J Neurosci 25: 3002-3008.

Received May 13, 2015; accepted in revised form November 9, 2015. 


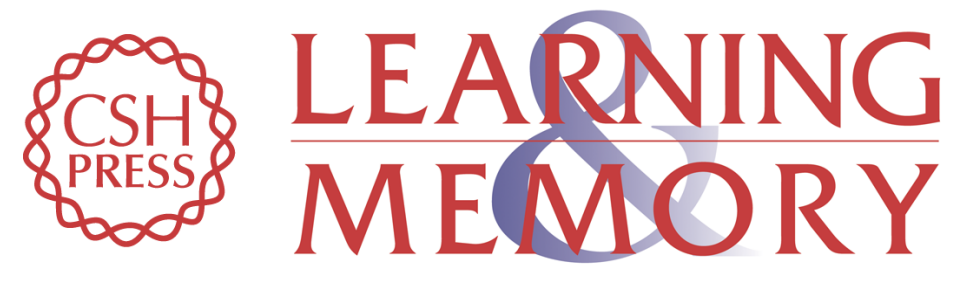

\section{Recovering and preventing loss of detailed memory: differential rates of forgetting for detail types in episodic memory}

Melanie J. Sekeres, Kyra Bonasia, Marie St-Laurent, et al.

Learn. Mem. 2016, 23:

Access the most recent version at doi:10.1101/Im.039057.115

\section{Supplemental http://learnmem.cshlp.org/content/suppl/2016/01/06/23.2.72.DC1 Material}

References This article cites 95 articles, 10 of which can be accessed free at: http://learnmem.cshlp.org/content/23/2/72.full.html\#ref-list-1

Creative This article is distributed exclusively by Cold Spring Harbor Laboratory Press for the Commons first 12 months after the full-issue publication date (see

License http://learnmem.cshlp.org/site/misc/terms.xhtml). After 12 months, it is available under a Creative Commons License (Attribution-NonCommercial 4.0 International), as described at http://creativecommons.org/licenses/by-nc/4.0/.

Email Alerting Receive free email alerts when new articles cite this article - sign up in the box at the Service top right corner of the article or click here. 